\title{
Rhinomanometric reference intervals for normal total nasal airflow resistance*
}

\author{
J. Merkle, L. Kohlhas, G. Zadoyan, R. Mösges, M. Hellmich \\ Institute of Medical Statistics, Informatics and Epidemiology (IMSIE), University of Cologne, Cologne, Germany
}

Rhinology 52: 292-299, 2014

DOI:10.4193/Rhino13.220

*Received for publication:

December 13, 2013

Accepted: May 26, 2014

\begin{abstract}
Background: Reference intervals (RIs) or mean values for normal total nasal airflow resistance are essential for the diagnosis of nasal obstruction. Data relating to nasal airflow are not standardised, and valid and reliable Rls do not exist for the time being. This meta-analysis aimed to determine such "standard"95\%-RIs.
\end{abstract}

Methodology: Research of related literature listed in Medline, Embase, Cochrane, and Web of Science databases.

Results: Airflow resistance data were gathered from 38 studies using active anterior rhinomanometry at a differential pressure of $150 \mathrm{~Pa}$ to examine patients under congested and decongested mucosal conditions. In the meta-analysis overall values and RIs for normal total nasal airflow resistance under congested nasal mucosal conditions were calculated for all subjects at $0.25 \mathrm{~Pa} /$ $\mathrm{cm}^{3} / \mathrm{s}\left(95 \%-\mathrm{Rl} 0.10-0.40 \mathrm{~Pa} / \mathrm{cm}^{3} / \mathrm{s}\right)$, adults regardless of gender at $0.25 \mathrm{~Pa} / \mathrm{cm}^{3} / \mathrm{s}\left(95 \%-\mathrm{Rl} 0.12-0.38 \mathrm{~Pa} / \mathrm{cm}^{3} / \mathrm{s}\right), \mathrm{men}$ at $0.24 \mathrm{~Pa} / \mathrm{cm}^{3} / \mathrm{s}$ (95\%-RI 0.09-0.39Pa/ $\left.\mathrm{cm}^{3} / \mathrm{s}\right)$, and women at $0.26 \mathrm{~Pa} / \mathrm{cm}^{3} / \mathrm{s}\left(95 \%-\mathrm{Rl} 0.08-0.44 \mathrm{~Pa} / \mathrm{cm}^{3} / \mathrm{s}\right)$. Asian, African and Caucasian ethnic groups exhibited rising airflow resistance mean values: $0.23 \mathrm{~Pa} / \mathrm{cm}^{3} / \mathrm{s}\left(95 \%-\mathrm{RI} 0.08-0.39 \mathrm{~Pa} / \mathrm{cm}^{3} / \mathrm{s}\right), 0.25 \mathrm{~Pa} / \mathrm{cm}^{3} / \mathrm{s}\left(95 \%-\mathrm{RI} 0.11-0.38 \mathrm{~Pa} / \mathrm{cm}^{3} / \mathrm{s}\right)$ and $0.26 \mathrm{~Pa} / \mathrm{cm}^{3} / \mathrm{s}\left(95 \%-\mathrm{Rl} 0.13-0.38 \mathrm{~Pa} / \mathrm{cm}^{3} / \mathrm{s}\right)$, respectively. Lower overall mean values resulted under decongested nasal mucosal conditions.

Conclusion: The reference intervals and mean values ascertained in this meta-analysis improve the diagnosis of nasal obstruction and may represent a useful supplement in existing guidelines for the standardisation of rhinomanometric measurements.

Key words: rhinomanometry, normal values, nasal patency, nasal resistance, guidelines

\section{Introduction}

Standard reference intervals (RIs) or mean values, such as those for lung function or temperature, aid the physician in assessing a patient's health condition quickly and objectively ${ }^{(1)}$. With respect to the evaluation of nasal obstruction, which can have a considerable impact on patients' quality of life, no generally recognised Rls and mean values exist. Rhinomanometry is a measurement method frequently applied to determine nasal airflow resistance. This procedure makes it possible to obtain sound data despite the anatomical complexity of the nose and its many external and internal impacting factors, such as conge- sted and decongested nasal mucosa.

Normal nasal patency in healthy subjects can be determined by measuring airflow resistance via rhinomanometry. The data obtained can be evaluated in a meta-analysis and thereby provide physicians with "standard" Rls and mean values useful for the diagnosis of nasal obstruction.

Making a considerable contribution to the conformity of measurement results was the standardisation of the measurement process. In 1984, rhinologists from around the world assembled upon the initiative of E. B. Kern to form the "International 
Standardization Committee on the Objective Assessment of the Upper Nasal Airways" (ISCOANA) with the purpose of harmonising the measurement procedure and thus making measurement results comparable worldwide ${ }^{(2)}$. Consequently, the measurement process was standardised. Based on the individual and phylogenetic anatomy and functionality of the nose, however, overall RIs and mean values for normal nasal patency are still lacking with regard to specific variables.

This meta-analysis aimed to determine 95\%-RIs and mean values for normal total nasal airflow resistance. General standard Rls and mean values were to be investigated, taking demographic and clinical information into account. Such data could serve as a supplement to the ISCOANA guidelines and provide the practising physician with a dependable diagnostic aid for making an objective evaluation of the nasal obstruction of his/ her patients. Without such "normal" ranges and mean values, the physician cannot assess the severity of nasal obstruction reliably. RIs and mean values for normal total nasal airflow resistance, as measured via active anterior rhinomanometry at a pressure of $150 \mathrm{~Pa}$ under congested and decongested nasal mucosal conditions, were calculated in a meta-analysis of 38 identified trials. RIs and mean values were determined for all subjects, both genders, men, women, children, and for the Asian, Caucasian, and African ethnic groups. Data collected from trials using the Broms method, active posterior rhinomanometry, and at a differential pressure of $75 \mathrm{~Pa}$ were likewise calculated in the meta-analysis.

\section{Materials and methods}

A systematic search for published trials listed in the databases of Medline, Embase, Cochrane, Web of Science and for secondary literature was conducted from 1 October 2012 to 30 March 2013. The search terms used were: 'rhinomanometry,'nasal patency,' 'nasal resistance,'nasal obstruction,' guidelines,'standardization, and 'normal values.'The search was limited to studies published in English, French, and German. The studies were included only if they reported values measured via rhinomanometry for nasal airflow resistance in healthy subjects. Included were healthy patients, healthy control groups, healthy subjects following nasal septum surgery, and healthy subjects with no nasal obstruction. Besides criteria pertaining to content, formal criteria also needed to be fulfilled, such as mention of the patient population size, mean values and standard deviation of the nasal airflow resistance and of the differential pressure used in rhinomanometric measurements.

In particular, data were analysed in trials that were conducted with active anterior rhinomanometry (AAR) using a differential pressure of $150 \mathrm{~Pa}$ under congested and decongested nasal mucosal conditions, specifically according to gender (male, female, both genders together, and all subjects), ethnic group (Asian, Caucasian, and African) and according to age, whereby a dif- ferentiation was made between subjects 18 years of age or older and those under 18 . Studies that applied a differential pressure of $75 \mathrm{~Pa}$ and trials that used active posterior rhinomanometry (APR) were also analysed.

To enable a comparison of airflow resistances, the various units used in the studies were converted to the $\mathrm{SI}$ unit $\mathrm{Pa} / \mathrm{cm}^{3} / \mathrm{s}$.

"Forest" plots of reference intervals and mean values of normal total nasal airflow resistance (NNAFRt) with overall result from random-effects meta-analysis ${ }^{(3)}$ are given. Grey shaded areas represent $95 \%$ confidence intervals of study-specific RI endpoints ${ }^{(4)}$, areas at the bottom represent $95 \%$ confidence intervals of overall endpoints, squares represent study-specific interval mid points (i.e. mean values) where size corresponds to meta-analysis weight, and the diamond represents the overall mid point with $95 \%$ confidence interval. To assess the extent of inconsistency among the studies' results the $\mathrm{I}^{2}$ statistic and a test of heterogeneity based on the $\mathrm{Q}$ statistic were calculated. Statistical analysis was done with the software " $R$ " (R Foundation for Statistical Computing, Vienna, Austria; package rmeta).

\section{Results}

Of the 62 identified studies, 61 were prospective and one was retrospective. Thirty-eight studies were chosen for the metaanalysis. All in all, 95\% reference intervals and mean values for normal total nasal airflow resistance were analysed for 8,707 healthy subjects.

The titles and abstracts of 9,754 publications from 1979 to 2013

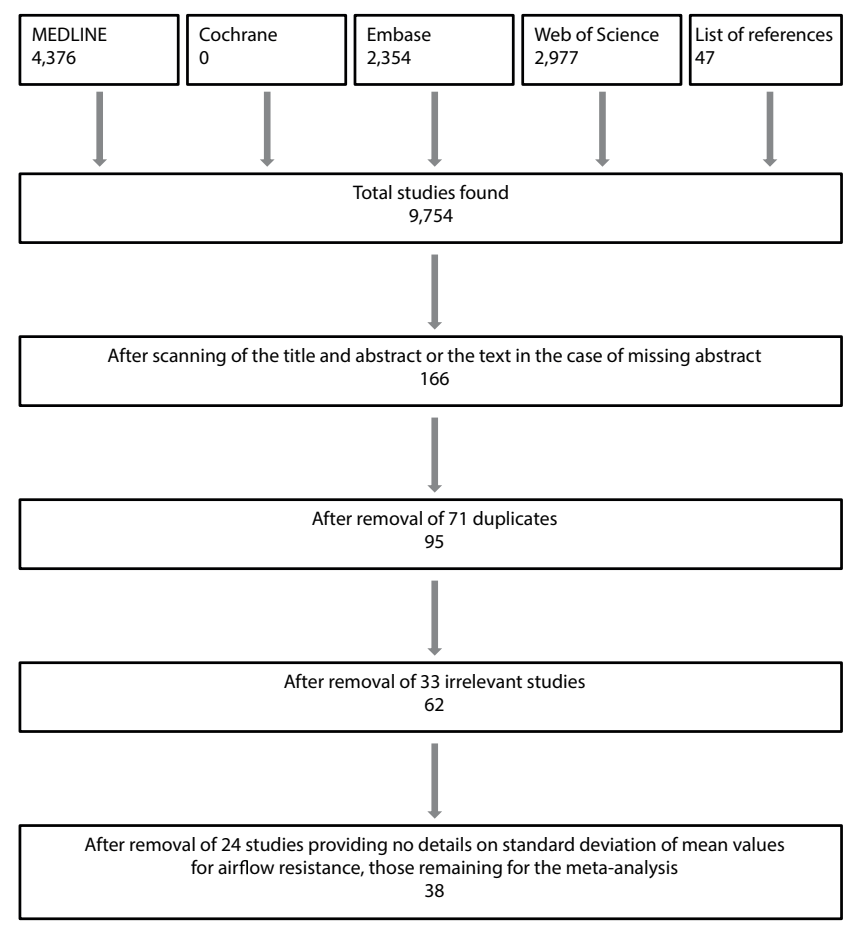

Figure 1. Flowchart of the search for literature. 
Table 1. Published mean values and overall result from random-effects meta-analysis of normal total nasal airflow resistance (NNAFRt) with standard deviation (SD) and reference interval (RI). Published mean values were measured using active anterior rhinomanometry at a pressure of $150 \mathrm{~Pa}$ in all subjects under congested nasal mucosal conditions.

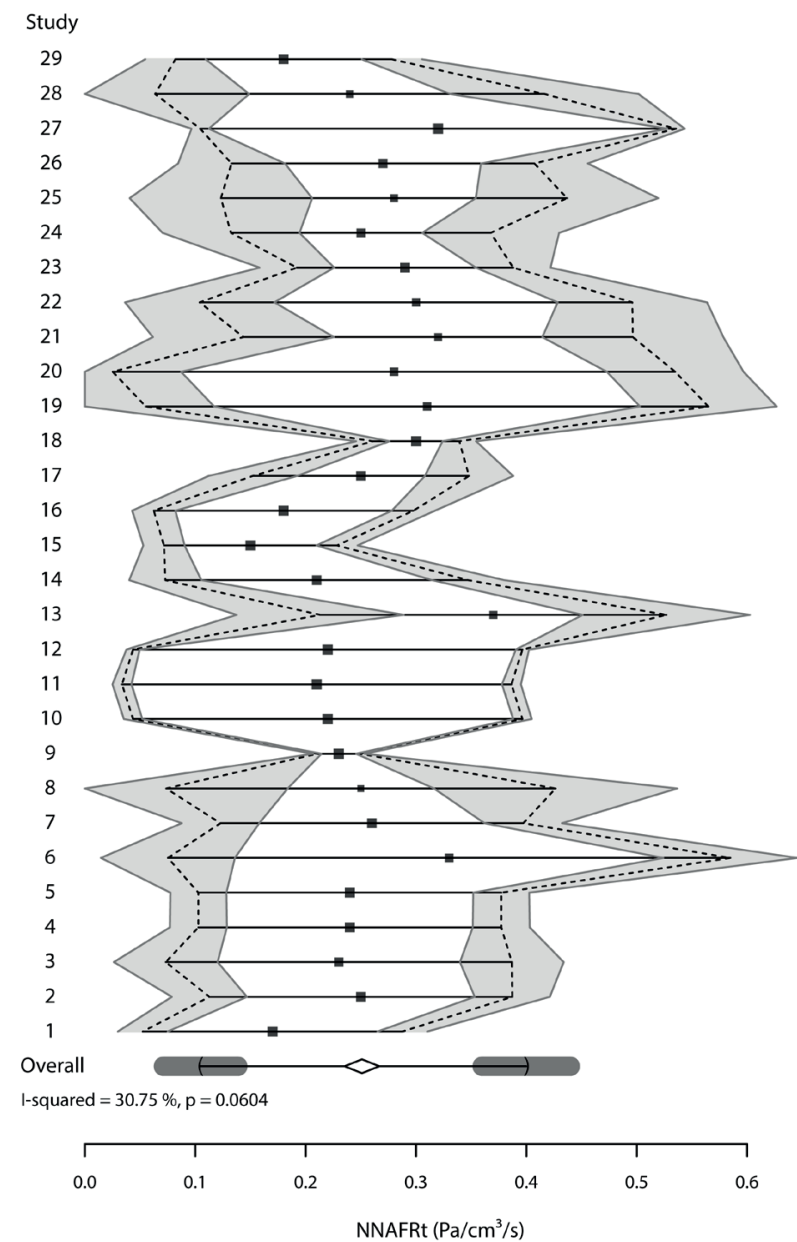

Figure 2. Forest plot of reference intervals with overall result from random-effects meta-analysis based on published mean values for normal total nasal airflow resistance (NNAFRt) measured using active anterior rhinomanometry at a pressure of $150 \mathrm{~Pa}$ in all subjects under congested nasal mucosal conditions (see section "Material and Methods" for details)

were scanned for relevance according to the inclusion criteria. Studies that did not fulfil the inclusion criteria and systematic reviews that did not constitute clinical trials, guidelines or duplications of studies were excluded immediately, yielding 166 relevant studies from all databases and reference lists. After removing 71 duplicates, 95 studies remained.

Another 33 trials were excluded because they did not present exact mean values or it was unclear whether the subjects were healthy or only correlation values were given or they applied

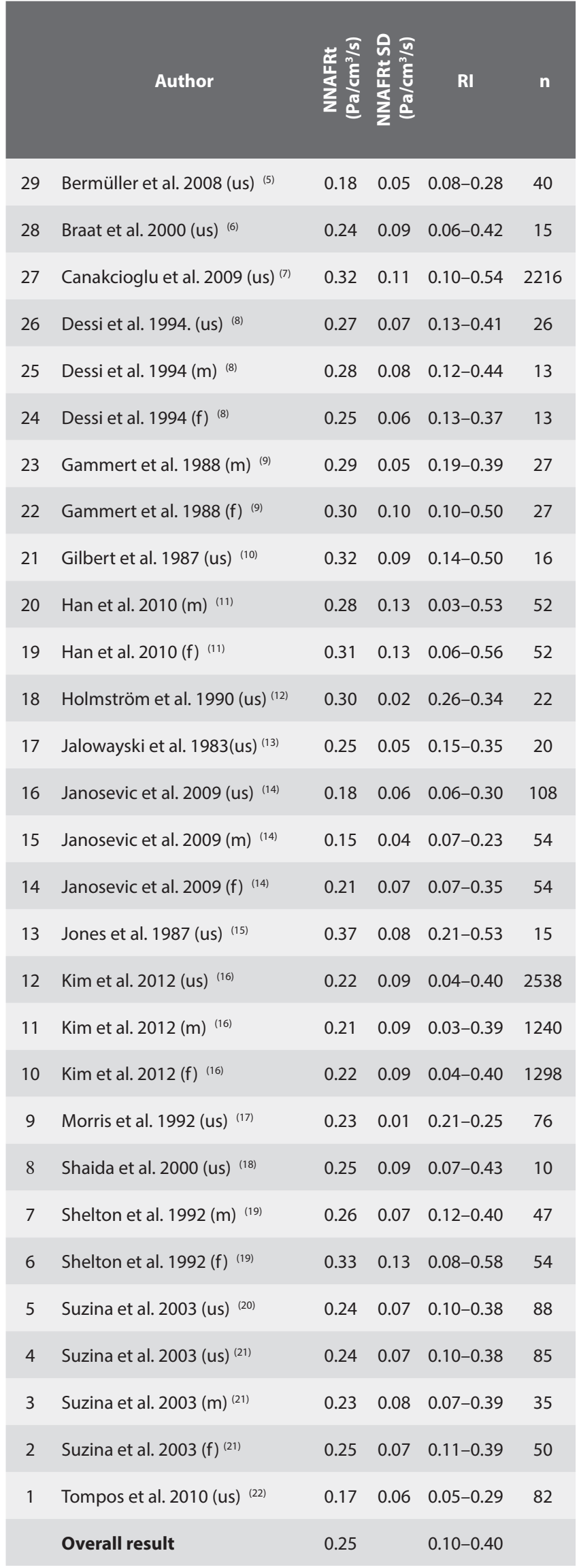

us (unisex) $=$ both genders combined, $m=$ male, $f=$ female 
Table 2. Published mean values and overall result from random-effects meta-analysis of normal total nasal airflow resistance (NNAFRt) with standard deviation (SD) and reference interval (RI). Published mean values were measured using active anterior rhinomanometry at a pressure of $150 \mathrm{~Pa}$ in all subjects under decongested nasal mucosal conditions.

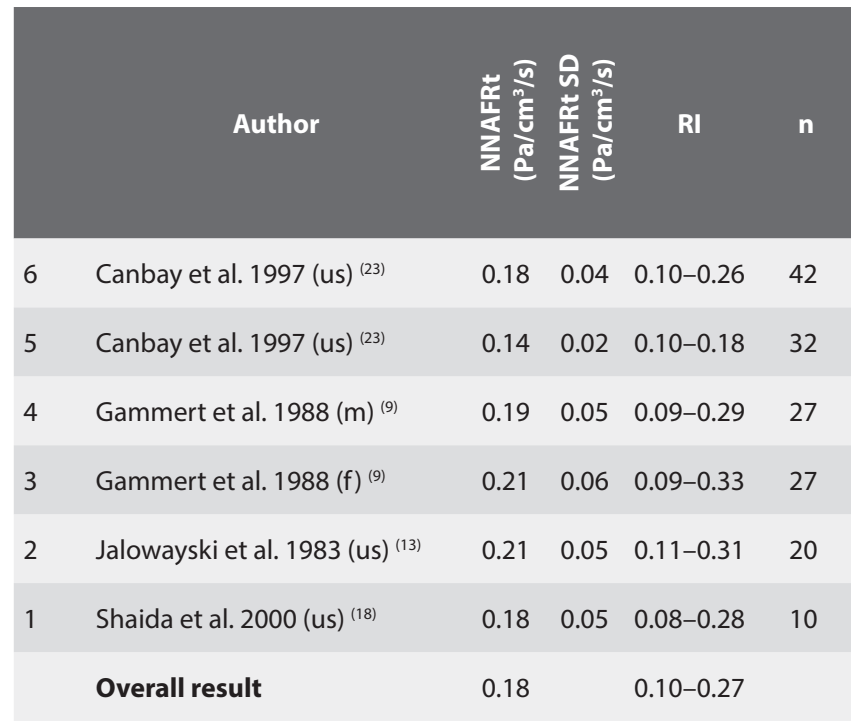

us (unisex) $=$ both genders combined, $m=$ male, $f=$ female, numbers 5 and $6=$ values of different groups

another measuring methods. Thus, 38 prospective studies were selected for the meta-analysis (Figure 1).

The airflow resistance values, measured using active anterior rhinomanometry at a differential pressure of $150 \mathrm{~Pa}$, were analysed from a total of 8,373 subjects under congested nasal mucosal conditions. An overall result of $0.25 \mathrm{~Pa} / \mathrm{cm}^{3} / \mathrm{s}$ with a $95 \%-\mathrm{Rl}$ of $0.10-0.40 \mathrm{~Pa} / \mathrm{cm}^{3} / \mathrm{s}$ was found for normal total nasal airflow resistance across all data sets for all subjects (Figure 2 and Table 1).

The airflow resistance values, measured using active anterior rhinomanometry at a differential pressure of $150 \mathrm{~Pa}$, were analysed from a total of 158 subjects under decongested nasal mucosal conditions. An overall result of $0.18 \mathrm{~Pa} / \mathrm{cm}^{3} / \mathrm{s}$ with a $95 \%-R l$ of $0.10-0.27 \mathrm{~Pa} / \mathrm{cm}^{3} / \mathrm{s}$ was found for normal total nasal airflow resistance throughout all data sets for all subjects (Figure 3 and Table 2).

Summary of the reference intervals and mean values calculated in the meta-analysis

All results from the meta-analysis are summarised in Table 3.

\section{Distribution of demographic and clinical variables investi-} gated in the studies

The list that breaks down the 62 studies according to demograp-

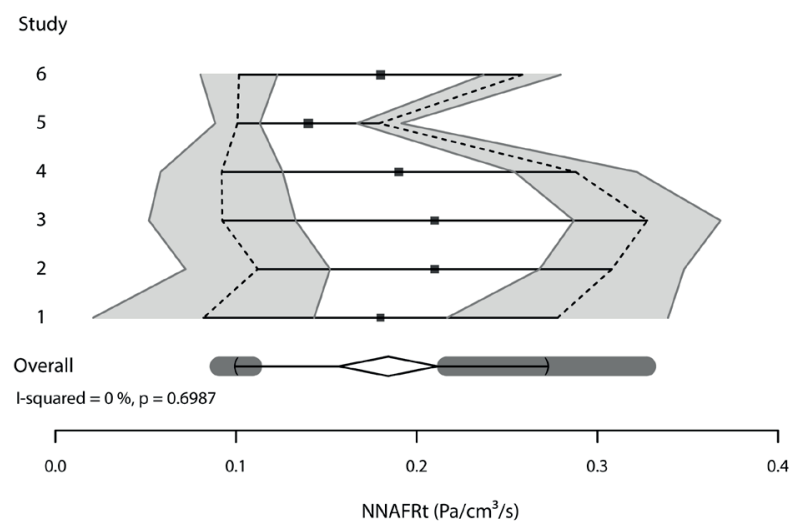

Figure 3. Forest plot of reference intervals with overall result from random-effects meta-analysis based on published mean values for normal total nasal airflow resistance (NNAFRt) measured using active anterior rhinomanometry at a pressure of $150 \mathrm{~Pa}$ in all subjects under decongested nasal mucosal conditions (see section "Material and Methods" for details).

hic and clinical information shows the various distributions of the studies as per the parameters essential for determining the differentiating airflow resistance values (Table 4).

\section{Discussion}

In interpreting the results, one must not disregard the fact that the sample size in the studies varied between 10 and 2,538 subjects. This circumstance was in fact taken into account when calculating the meta-analysis. All studies were also chosen carefully; it cannot be completely ruled out, however, that all relevant studies were found. Most trials were observational studies, which is normal in diagnostic studies involving medical devices, and therefore sufficed for the objective of the present paper.

\section{Gender}

Gender can have an impact on nasal patency. Men generally have a lower nasal airflow resistance than women ${ }^{(19,20,24-27)}$. This observation is supported by the results of the present meta-analysis, in which men had a normal total nasal airflow resistance of $0.24 \mathrm{~Pa} / \mathrm{cm}^{3} / \mathrm{s}\left(95 \%-\mathrm{RI} 0.09-0.39 \mathrm{~Pa} / \mathrm{cm}^{3} / \mathrm{s}\right)$ and women $0.26 \mathrm{~Pa} /$ $\mathrm{cm}^{3} / \mathrm{s}\left(95 \%-\mathrm{Rl} 0.08-0.44 \mathrm{~Pa} / \mathrm{cm}^{3} / \mathrm{s}\right)$ measured under congested nasal mucosal conditions at $150 \mathrm{~Pa}$. This may be attributed to the fact that men have a larger nose and thereby a larger nasal volume than women. Under decongested conditions men also have a lower nasal airflow resistance at $0.19 \mathrm{~Pa} / \mathrm{cm}^{3} / \mathrm{s}(95 \%-\mathrm{Rl}$ $\left.0.09-0.29 \mathrm{~Pa} / \mathrm{cm}^{3} / \mathrm{s}\right)$ than women at $0.21 \mathrm{~Pa} / \mathrm{cm}^{3} / \mathrm{s}(95 \%-\mathrm{RI} 0.08-$ $0.34 \mathrm{~Pa} / \mathrm{cm}^{3} / \mathrm{s}$ ).

One would expect that the value for both genders combined $\left(0.25 \mathrm{~Pa} / \mathrm{cm}^{3} / \mathrm{s}\right.$ with $\left.95 \%-\mathrm{Rl} 0.12-0.38 \mathrm{~Pa} / \mathrm{cm}^{3} / \mathrm{s}\right)$ would lie between that for men $\left(0.24 \mathrm{~Pa} / \mathrm{cm}^{3} / \mathrm{s}\right)$ and that for women $(0.26$ 
Table 3. Summary of the reference intervals calculated in the meta-analysis based on the mean values (MVMA) and reference intervals (RI) for normal total nasal airflow resistance derived from the rhinomanometry values documented in the included studies.

\begin{tabular}{|c|c|c|c|c|c|}
\hline \multicolumn{3}{|c|}{ Congested } & \multicolumn{3}{|c|}{ Decongested } \\
\hline & $\operatorname{MVMA}\left(\mathrm{Pa} / \mathrm{cm}^{3} / \mathrm{s}\right)$ & $95 \%-\mathrm{RI}\left(\mathrm{Pa} / \mathrm{cm}^{3} / \mathrm{s}\right)$ & & $\operatorname{MVMA}\left(\mathrm{Pa} / \mathrm{cm}^{3} / \mathrm{s}\right)$ & $95 \%-\mathrm{Rl}\left(\mathrm{Pa} / \mathrm{cm}^{3} / \mathrm{s}\right)$ \\
\hline \multicolumn{6}{|c|}{ Gender } \\
\hline \multirow[t]{4}{*}{$\mathrm{AAR}, 150 \mathrm{~Pa}$} & tot $=0.25$ & $0.10-0.40$ & $\mathrm{AAR}, 150 \mathrm{~Pa}$ & tot $=0.18$ & $0.10-0.27$ \\
\hline & us $=0.25$ & $0.12-0.38$ & & us $=0.18$ & $0.10-0.25$ \\
\hline & $m=0.24$ & $0.09-0.39$ & & $m=0.19^{*}$ & $0.09-0.29$ \\
\hline & $f=0.26$ & $0.08-0.44$ & & $f=0.21^{*}$ & $0.08-0.34$ \\
\hline \multicolumn{6}{|c|}{ Ethnic group } \\
\hline \multirow[t]{3}{*}{ AAR, $150 \mathrm{~Pa}$, us } & Cauc $=0.26$ & $0.13-0.38$ & $\mathrm{AAR}, 150 \mathrm{~Pa}$, us & Cauc $=0.19$ & $0.09-0.29$ \\
\hline & Asian $=0.23$ & $0.08-0.39$ & & Asian $=\mathrm{n} / \mathrm{s}$ & $n / s$ \\
\hline & Afric $=0.25$ & $0.11-0.38$ & & Afric $=0.16$ & $0.05-0.31$ \\
\hline \multicolumn{6}{|c|}{ Age } \\
\hline \multirow[t]{2}{*}{$\mathrm{AAR}, 150 \mathrm{~Pa}$, us } & $\geq 18=0.23$ & $0.11-0.37$ & $\mathrm{AAR}, 150 \mathrm{~Pa}$, us & $\geq 18=0.20$ & $0.10-0.30$ \\
\hline & $\leq 18=n / s$ & $\mathrm{n} / \mathrm{s}$ & & $\leq 18=0.24$ & $0.11-0.37$ \\
\hline \multicolumn{6}{|c|}{ Special parameters and measurement methods - Gender } \\
\hline $\mathrm{AAR}, 75 \mathrm{~Pa}$, us & us $=0.19$ & $0.03-0.34$ & & & \\
\hline APR, us & us $=0.19$ & $0.06-0.34$ & & & \\
\hline \multicolumn{6}{|c|}{ Broms method - Gender } \\
\hline \multirow[t]{3}{*}{ AAR, Broms } & $\mathrm{us}=0.18$ & $0.05-0.34$ & AAR, Broms & $\mathrm{us}=0.12$ & $0.05-0.21$ \\
\hline & $\mathrm{m}=0.18^{*}$ & $0.02-0.38$ & & $\mathrm{~m}=0.07$ & $0.00-0.16$ \\
\hline & $f=n / s$ & $\mathrm{n} / \mathrm{s}$ & & $f=n / s$ & $n / s$ \\
\hline
\end{tabular}

tot $=$ total, entire group of subjects, us (unisex) = both genders combined, $m=$ male, $f=$ female, congested $=$ under untreated nasal mucosal conditions, decongested $=$ under treated nasal mucosal conditions, AAR = active anterior rhinomanometry, APR $=$ active posterior rhinomanometry, 150 Pa $=$ differential pressure of $150 \mathrm{~Pa}, 75 \mathrm{~Pa}=$ differential pressure of $75 \mathrm{~Pa}, \mathrm{n} / \mathrm{s}=$ not specified, ${ }^{*} 1$ study.

$\left.\mathrm{Pa} / \mathrm{cm}^{3} / \mathrm{s}\right)$. However, this is not the case. The reason for this discrepancy could be that twice as many trials with both genders combined were included in the meta-analysis than those with men and women. Based on the overall lower number of studies with values for men only and for women only, the values determined could be considered inaccurate from a statistical perspective. The mean value for normal total nasal airflow resistance at $0.25 \mathrm{~Pa} / \mathrm{cm}^{3} / \mathrm{s}$ for all subjects across all data sets, however, lies between those of men and women as expected.

Under decongested nasal mucosal conditions, the mean reference value for normal total nasal airflow resistance was 0.18
$\mathrm{Pa} / \mathrm{cm}^{3} / \mathrm{s}$ for all subjects across all data sets. It was therefore situated below the mean reference value for men $\left(0.19 \mathrm{~Pa} / \mathrm{cm}^{3} / \mathrm{s}\right)$ and women $\left(0.21 \mathrm{~Pa} / \mathrm{cm}^{3} / \mathrm{s}\right)$. This low value can be attributed to the fact that only one study each was found for men and for women. For both genders together, a mean reference value for normal total nasal airflow resistance of $0.18 \mathrm{~Pa} / \mathrm{cm}^{3} / \mathrm{s}$ was calculated, which for the same reasons lay under the values for men and women. Overall, the reference values for all subjects and those for both genders together are lower under decongested nasal mucosal conditions than the reference values for men and women separately under congested nasal mucosal conditions. 
Table 4. Distribution of the selected 62 trials according to demographic and clinical variables (multiple nominations are possible).

\begin{tabular}{|c|c|c|c|}
\hline Variable & $\begin{array}{c}\text { Number } \\
\text { of } \\
\text { studies }\end{array}$ & Variable & $\begin{array}{c}\text { Number } \\
\text { of } \\
\text { studies }\end{array}$ \\
\hline Gender & & Measuring period & 5 \\
\hline Male & 13 & Measurements (n) & 11 \\
\hline Female & 7 & Breaths & 7 \\
\hline Both genders & 60 & Decongestion & 28 \\
\hline Ethnic group & & Congestion & 51 \\
\hline Caucasian & 56 & $\begin{array}{l}\text { According ISCOANA } \\
\text { guidelines }\end{array}$ & 32 \\
\hline Asian & 6 & Hygiene & 26 \\
\hline African & 3 & Device & 42 \\
\hline Climate & & Calibration & 29 \\
\hline Cold & 0 & Rhinomanometry & \\
\hline Warm-dry & 0 & Active anterior RMM & 59 \\
\hline Warm-humid & 0 & Active posterior RMM & 9 \\
\hline Age & & Passive anterior RMM & 1 \\
\hline Children & 3 & Mask & \\
\hline Adults & 48 & Anaesthesia mask & 12 \\
\hline Not specified & 15 & Face mask & 27 \\
\hline Weight & 6 & Not specified & 23 \\
\hline Height & 5 & $\begin{array}{l}\text { Fixation of pressure } \\
\text { measuring tube }\end{array}$ & 27 \\
\hline MCA & 7 & According ISCOANA & 20 \\
\hline NV & 5 & Tape & 10 \\
\hline \multirow[t]{2}{*}{ Nasal index } & 0 & Tube/ Nozzle & 12 \\
\hline & & Not specified & 20 \\
\hline BMI* & 4 & Pressure & \\
\hline Medical history & 62 & $150 \mathrm{~Pa}$ & 44 \\
\hline Room temperature & 9 & $75 \mathrm{~Pa}$ & 9 \\
\hline Room humidity & 9 & $100 \mathrm{~Pa}$ & 3 \\
\hline Measuring position & 40 & Broms & 2 \\
\hline Break & 32 & Not specified & 4 \\
\hline
\end{tabular}

Age

The nose enlarges during normal growth from child to adult ${ }^{28-}$ ${ }^{31)}$. Thus, adults have better nasal patency than children ${ }^{(24,32)}$. No study could be found that examined children under congested nasal mucosal conditions. Under decongested nasal conditions, an airflow resistance value of $0.24 \mathrm{~Pa} / \mathrm{cm}^{3} / \mathrm{s}(95 \%-\mathrm{RI} 0.11-0.37$ $\mathrm{Pa} / \mathrm{cm}^{3} / \mathrm{s}$ ) was calculated from the data of two studies involving children. This points to children having a higher level of airflow resistance than adults.

\section{Variables and nasal airflow resistance measurements} Demographic and clinical information is important for obtaining differentiated and significant airflow resistance measurements. In the meta-analysis, 17 studies were identified that reported values for both genders. Seven studies each documented the values for men and women separately. In future, it is essential to design differentiated studies that determine the airflow resistance values separately for men and women to obtain gender-specific values. Furthermore, only a few studies were found involving Asian and African subjects in contrast to studies with Caucasian subjects. Here, too, it is necessary to adjust the number of studies with African and Asian subjects to those with Caucasian participants. Attention should be paid, however, to the homogeneity of the ethnic groups.

Also, children are rarely considered in rhinomanometric studies and the elderly not at all. To counterbalance this deficit, a larger number of studies that more strongly differentiate the demographic variables in rhinomanometric measurements are needed in the future. Especially individual variables such as weight, height or Body Mass Index (BMI) and nasal anthropometric measures such as nasal index (NI), nasal volume (NV), mean cross-sectional area (MCA) of the nose should be taken into account in airflow resistance measurements in future study designs. Also measurement variables such as ambient air temperature, ambient air humidity, measuring position, measuring interval, measuring period, number of breaths or calibration are important and should be included (Table 4).

Thirty two of the identified studies followed ISCOANA recommendations, showing that many scientists already orient themselves toward these guidelines and thus contribute to the worldwide general comparability of rhinomanometric measurements. Differences in the clinical and especially in the measuring values may have occurred because no uniform calibration procedure existed for the rhinomanometers used in the initial studies. A future objective should therefore be to obtain equal airflow resistance values based on a uniform, artificial nose model serving to calibrate the various devices.

Likewise, to be able to better compare the results, studies should document the ambient climatic conditions during rhinomanometric measurements. Since none of the studies had taken this aspect into account, the parameter of climate could not be 
included in the meta-analysis.

\section{Diagnosis of nasal obstruction}

With the help of this systematic review, one can access scientifically determined meta-analysis values - $95 \%$ reference intervals and mean values - that have been calculated from currently available studies. These values are also specified for different populations (gender, age, ethnic groups) and can potentially lead to standardization of techniques and devices and a clearer definition of normal, borderline and obstructed nasal passage.

\section{Conclusion}

This meta-analysis made it possible to determine overall reference intervals and mean values for normal total nasal airflow resistance using active anterior rhinomanometry under congested and decongested nasal mucosal conditions. Overall reference intervals and mean values were generated with respect to gender, age and ethnic group.

With the help of this systematic review, the physician can access scientifically determined meta-analysis values - $95 \%$ reference intervals and mean values -, which can also serve as a useful supplement to the ISCOANA guidelines.

This paper should be regarded first of all as a contribution to the evaluation of systematic rhinomanometric overall reference intervals and mean values that need to be optimised in the future when new studies that more strongly differentiate according to the specified parameters to yield more data.

\section{Acknowledgements}

We thank Gena Kittel for translating the original German manuscript into English.

\section{Authorship contribution}

Participated in research design: JM; Conducted literature research: JM, RM, GZ; Performed statistical analysis: MH, LK, JM; Wrote or contributed to the writing of the manuscript: $\mathrm{MH}, \mathrm{JM}$, RM

\section{Conflicts of Interest}

No conflict of interest is to be declared.

\section{References}

1. Moore M, Eccles R. Normal nasal patency: problems in obtaining standard reference values for the surgeon. J Laryngol Otol 2012; 126: 563-569.

2. Clement PA. Committee report on standardization of rhinomanometry. Rhinology 1984; 22: 151-155

3. DerSimonian R, Laird N. Meta-analysis in clinical trials. Control Clin Trials. 1986; 7: 177 188.

4. Bland JM, Altman DG. Measuring agreement in method comparison studies. Stat Methods Med Res 1999; 8: 135-160.

5. Bermüller $C$, Kirsche $H$, Rettinger $G$ Riechelmann H. Diagnostic accuracy of peak nasal inspiratory flow and rhinomanometry in functional rhinosurgery. Laryngoscope 2008; 118: 605-610.

6. Braat JP, Fokkens WJ, Mulder PG, Kianmaneshrad N, Rijntjes E, Gerth van Wijk $\mathrm{R}$. Forced expiration through the nose is a stimulus for NANIPER but not for controls. Rhinology 2000; 38: 172-176.

7. Canakcioglu S, Tahamiler R, Saritzali G Isildak H, Alimoglu Y. Nasal patency by rhinomanometry in patients with sensation of nasal obstruction. Am J Rhinol Allergy 2009; 23: 300-302

8. Dessi P, Sambuc R, Moulin G, Ledoray V, Cannoni M. Effect of heavy smoking on nasal resistance. Acta Otolaryngol 1994; 114: 305-310

9. Gammert C, Hampl K, Herrmann P. [Normal values in rhinomanometry]. HNO 1988; 36: 399-405.

10. Gilbert AN, Rosenwasser AM. Biological rhythmicity of nasal airway patency: a re-examination of the 'nasal cycle'. Acta Otolaryngol 1987; 104: 180-186.

11. Vogt K, Jalowayski AA, Althaus W. et al. 4-Phase-Rhinomanometry (4PR) -basics and practice 2010. Rhinol Suppl 2010: 1-50.

12. Holmstrom M, Scadding GK, Lund VJ, Darby YC. Assessment of nasal obstruction. A comparison between rhinomanometry and nasal inspiratory peak flow. Rhinology 1990; 28: 191-196.

13. Jalowayski AA, Yuh YS, Koziol JA, Davidson TM. Surgery for nasal obstruction--evaluation by rhinomanometry. Laryngoscope 1983; 93: 341-345

14. Janosevic L, Dotlic J, Janosevic S, Dudvarski Z, Milovanovic A, Pendjer I. Computerized rhinomanometry: a study of total nasal resistance normal values. Acta Chir lugosl 2009; 56: 51-54.

15. Jones AS, Lancer JM, Stevens JC, Beckingham E. Rhinomanometry: do the anterior and posterior methods give equivalent results? Clin Otolaryngol Allied Sci 1987; 12: 109-114

16. Kim SJ, Choi JH, Kim EJ et al. A Prospective Population-based Study of Total Nasal Resistance in Korean Subjects. Clin Exp Otorhinolaryngol 2012; 5: 39-43.

17. Morris S, Jawad MS, Eccles R. Relationships between vital capacity, height and nasal airway resistance in asymptomatic volunteers. Rhinology 1992; 30: 259-264.

18. Shaida AM, Kenyon GS. The nasal valves: changes in anatomy and physiology in normal subjects. Rhinology 2000; 38: 7-12.

19. Shelton DM, Eiser NM. Evaluation of active anterior and posterior rhinomanometry in normal subjects. Clin Otolaryngol Allied Sci
1992; 17: 178-182.

20. Suzina AH, Hamzah M, Samsudin AR. Objective assessment of nasal resistance in patients with nasal disease. J Laryngol Otol 2003; 117: 609-613.

21. Suzina AH, Hamzah M, Samsudin AR. Active anterior rhinomanometry analysis in normal adult Malays. J Laryngol Otol 2003; 117: 605-608.

22. Tompos T, Garai T, Zemplen B, Gerlinger I. Sensation of nasal patency compared to rhinomanometric results after septoplasty. Eur Arch Otorhinolaryngol 2010; 267: 18871891.

23. Canbay El, Bhatia SN. A comparison of nasal resistance in white Caucasians and blacks. Am J Rhinol 1997: 11: 73-75.

24. Papachristou A, Bourli E, Aivazi D et al. Normal peak nasal inspiratory flow rate values in Greek children and adolescents. Hippokratia 2008; 12: 94-97.

25. Ottaviano G, Scadding GK, Coles S, Lund VJ. Peak nasal inspiratory flow; normal range in adult population. Rhinology 2006; 44: 32-35.

26. Postema CA, Huygen PL, Lecluse RG, Wentges RT. The lateralization percentage as a measure of nasal flow asymmetry in active anterior rhinomanometry. Clin Otolaryngol Allied Sci 1980; 5: 165-170.

27. Millqvist $\mathrm{E}$, Bende $\mathrm{M}$. Reference values for acoustic rhinometry in subjects without nasal symptoms. Am J Rhinol 1998; 12: 341 343.

28. Abramson Z, Susarla S, Troulis M, Kaban L. Age-related changes of the upper airway assessed by 3-dimensional computed tomography. J Craniofac Surg 2009; 20 Suppl 1:657-663. 
29. Lindemann J, Sannwald D, Wiesmiller K Age-related changes in intranasal air conditioning in the elderly. Laryngoscope 2008; 118: 1472-1475.

30. Lindemann J, Tsakiropoulou E, Konstantinidis I, Lindemann K. Norma aging does not deteriorate nose-related quality of life: assessment with "NOSE" and "SNOT-20" questionnaires. Auris Nasus Larynx 2010; 37: 303-307.
31. Sforza C, Grandi G, De Menezes M, Tartaglia GM, Ferrario VF. Age- and sex-related changes in the normal human external nose. Forensic Sci Int 2011; 30: 204-205.

32. Prescott CA, Prescott KE. Peak nasal inspiratory flow measurement: an investigation in children. Int J Pediatr Otorhinolaryngol 1995: 32: 137-141.
Prof. Dr. med. Dipl.-Ing. Ralph Mösges Institute of Medical Statistics

Informatics and Epidemiology

University of Cologne

Lindenburger Allee 42

D- 50931 Cologne

Germany

Tel: +49-221-478-3456

Fax: +49-221-478-3465

E-mail: Ralph.moesges@uni-koeln.de 